\title{
Level of Individual Performance in the Context of Referencing Competency
}

\author{
Mohamad Rahimi Mohamad Rosman ${ }^{1}$, Amira Idayu Mohd Shukry ${ }^{2}$, Noor Azreen Alimin ${ }^{3}$, \\ Nurfatihah S Baharuddin ${ }^{4}$, Nik Nur Izzati Nik Rosli ${ }^{5}$, Noor Masliana Razlan ${ }^{6}$ \\ Universiti Teknologi MARA, Bukit Ilmu, 18500 Machang, Kelantan, Malaysia ${ }^{1,2,3,4,5,6}$

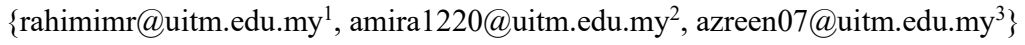

\begin{abstract}
Referencing competency is the knowledge, skills, and ability to use, edit, and disseminate different types of referencing standards and referencing software. Referencing competency helps to improve the quality of publication through proper citation and references. However, there is a scarcity of knowledge on the level of impact of referencing competency towards individual performance especially among undergraduate students. Therefore, the purpose of this study is to determine the level of individual performance in the context of referencing competency. A quantitative research instrument was developed, pretested, sent for pilot study before been analysed based on descriptive analysis using Statistical Package for Social Sciences (SPSS) version 26. The result shows that the respondents have a moderate level of task productivity and task satisfaction.
\end{abstract}

Keywords: referencing; task productivity; task satisfaction

\section{Introduction}

Competency is a term that differently defines in a different context. It is the ability to perform a task efficiently and effectively which include knowledge, skills, and value. Dario [1] defines competencies as a specific, recognizable, and measurable knowledge, skill, ability and/or other attributes related to deployments, such as the attitude, actions, physical ability that a human resource may possess and that is essential for the performance of an operation within a particular business context or material for it. Besides, Butler [2], and Kurz and Bartram [3], described competency as the ability to do something worthwhile well, such that the collection of qualities such as abilities, skills, beliefs, and attitudes are adequately applied to ensure the success of one's job performance. The ability to compose, understand and format the reference portion of their work is one of the essential skills that individuals require. Competencies must be relevant to the job requirements where students can do referencing well.

Competencies are important in measuring the success of tasks given. Therefore, students need to have skills and knowledge in doing references. Its need to be practised so that it can be used effectively in a wide range of appropriate situations, and at all the right times. In this COVID-19 pandemic, social distance is one of the keys to protecting ourselves. The changing environment is changing the environment in the higher institution where all the business is 
done online and most of the student's works are dominated by the changing technologies. Therefore, the changing situation demands new competencies for undergraduate and postgraduate student. Referencing competency is the knowledge, skills, and ability to perform and communicate the referencing standards and formats such as American Psychological Association (APA), the Modern Language Association (MLA), Chicago style, etc. Referencing competency helps to improve the quality of publication through proper citation and references.

Referencing is important for the undergraduate and postgraduate student to make sure that the writing was been cited well and no plagiarism issues occur. In a pandemic situation, the quality of education has changed. So, students themselves need to have competency in doing reference so that their work fulfils the academic requirement. It is possible to learn reference skills through training, whether technical or manual training. It is best to learn academic learning skills that include referencing skills in a setting where students can improve their learning skills within the discipline or faculty in which they want to study [4]. They also note in their research that most lecturers would give marks to ensure that their students use the right citation style in their assignments [4]. Students may also be issued a failing grade if other jobs are wrongly cited. The study showed that referencing competencies are important in academic writing and have a significant and positive relationship with individual performance.

In a pandemic situation, most of the student's works are dominated by technologies. Therefore, the changing environment in this pandemic situation demands new competencies for an undergraduate and postgraduate student. However, from the viewpoint of university students, there seems to be a shortage of studies on referencing competency individual performance. Previously, many studies on the issues on competencies have been studied by several researchers in the field of library and information management [5-7].

\section{Literature Review}

\subsection{Competency}

Van Der Klink \& Boon [8] define competency as a term that acquires a certain relevance from an academic perspective as they make it possible to close the gap between education and employment performance. Besides, Boyatzis [9] and Oosterbeek et al [10] described competencies is the fact that they can be developed through teaching and training. However, according to Okoye [11] competency is considered as knowledge, understanding, skills and attitudes to perform a job effectively. These elements are important for an individual to excel in his career and for this institution to thrive and succeed.

\subsection{Competencies of Library and Information Science (LIS) Professional}

Bronstein [12] says the dramatic changes experienced by the LIS profession in the last three decades are the result of rapidly evolving information and communication technology that has influenced the knowledge and skills required by LIS professionals working in libraries and information centres.

Partridge, Lee and Munro [13] recommend that librarians should look at things from a client's perspective and should strive to develop new relationships with customers as an equal partnership. Besides, Trembach et al. [14] asserted that information professionals should 
possess excessive leadership skills, creative skills, and the capability to work independently as well as be part of a team.

Also, Saunders [15] identified the core competencies required for reference librarians from the perspective of their employers. He claims that in addition to strong communication skills and customer service orientation, librarians are expected to have enough technical intelligence to at least solve problems if they do not develop new tools. Additionally, Robati and Singh [16] identified from the 122 skills and competencies LIS required by special librarians; these skills were later confirmed by a panel of experts in Iran, who identified information technology competencies as the most important skills, followed by interpersonal skills and research proficiencies.

Also, the comprehensive report of Chow et al. [17] surveyed public library directors who also gave high levels of traditional library skills such as reference and collection development, and who placed special emphasis on the need for teamwork, leadership, and service orientation. The report also found the need for a closer relationship between the LIS department and employers.

Yale University Library [18] has designed core competencies for the future work performance of its staff consisting of resources, interpersonal skills, information, purpose, and technology. In the survey, Thomas [19] determines the computer skills required by librarians. Skills in finding library materials in OPAC, referencing, and quoting, are highly demanded skills from beginning-level academic librarians to assist and assist users in completing their work, especially in academic writing.

\subsection{Referencing competencies}

Information or ideas from other people's work used in essay writing or academic reports must be acknowledged. Referencing is a way to give appreciation and credit to the writer that the author has borrowed words and ideas. By quoting the work of a particular scholar, the author acknowledges and respects the intellectual property rights of the researcher.

As students or academics or researchers, they can leverage the millions of ideas, views and arguments published by other writers, most of whom have spent years researching and writing. All they must do is acknowledge their contribution to the assignment or any academic writing. Therefore, referencing skills is one of the competencies that librarians should have as they are responsible for educating users, especially students, academics, and researchers to have good skills in making references for their academic writing.

Nickerson [20] in their paper discussing references or references is a powerful way for students to demonstrate the depth and breadth of their research, understanding, involvement and critical thinking on disciplinary ideas. Therefore, the ability to quote and cite students' writing effectively is very important in institutions where critical and deep thinking and the breadth of knowledge are assessed and evaluated. This deep involvement and critical involvement require students to demonstrate high order skills such as assessment, analysis, synthesis, and problem-solving, where students reflect and use information from a variety of sources. The skill is used to identify books, journal articles and other sources of information used when writing a paper. This briefly refers to the source of information in the text of the academic work, and by producing an appropriate list of alphabetical references (or bibliographies) at the end of the author's work. With the recent advancement of information and communication technology (ICT), the practice of citation and bibliography reference has become easier. As asserted by McCullen [21], to what extent, the paradigm of scientific communication, the dissemination of research findings includes the formats, methods and 
methodologies of reference have brought to great changes. The development and emergence of the Internet, alertness of copyright, plagiarism and the scientific value of research are some of the vital aspects that motivate both researchers and publishers to promote accurate material in academic writing. Nowadays, with the rapid advancement of technology, citation management tools or sometimes called citation managers, reference management tools, or reference managers enable users to store, organize, annotate, and share references for research [22].

\section{Methodology}

The conduct of this study is quantitative research using a questionnaire. An instrument was developed based on the previous instrument. The items were adopted and adapted to meet the objective of the research. Next, the instrument was sent for expert review. 5 experts involved in the expert review process, each with minimum qualification of Doctor of Philosophy, having more than 10 years of academic experience, and have knowledge on referencing through study or a paper publication. Each expert was given 2 weeks to complete the evaluation of the instrument. The content clarity and relevant index (CV-I) of Polit and Beck [23] were adopted for the purpose of clarity and relevance. Then, amendment and improvement were made to the instrument base on the response and suggestion of the experts. A pilot study was conducted involving 100 undergraduate students from one of the local universities in Malaysia. Following the success of the pilot study, a field data collection was conducted, a total of 292 valid responses were received and will be analysed using Statistical Package for Social Sciences (SPSS) version 26. The subsequent section will discuss the findings of the study.

\section{Results and Discussion}

The following subsection explains the finding of the study in three sections. First, the result of reliability analysis is presented. Second, the descriptive analysis of the demographic profiles of the respondents is provided. Third, the descriptive analysis of individual performances is presented.

\subsection{Reliability analysis of Individual Performance}

Reliability analysis was conducted to determine the reliability of the instrument. The following table 1 shows the reliability analysis for individual performance, measure in term of task productivity (TAP) and task satisfaction (TAS). The result shows a value ranging from 0.950 to 0.965 , indicating strong reliability as indicated by Nunnaly [24].

Table 1. Reliability analysis of Individual Performance in the context of Referencing Competency

\begin{tabular}{clc}
\hline Second-Order Construct & First-Order Construct & Cronbach Alpha \\
\hline \multirow{2}{*}{ Individual Performance } & Task Productivity & 0.965 \\
& Task Satisfaction & 0.950 \\
\hline
\end{tabular}




\subsection{Demographic Analysis}

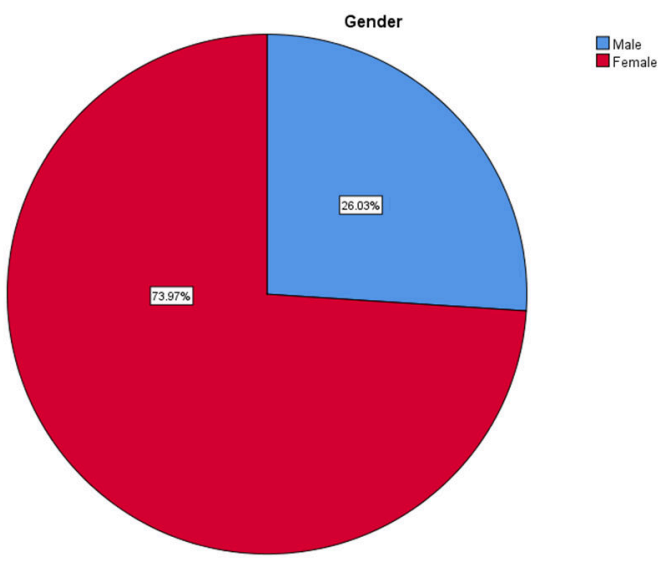

Fig. 1. Gender

The following figure 1 shows the distribution of respondent. A total of 292 valid response was received, collected using Google Form. From the final total of 292 responses, a total of 73.97 percent of the respondents are female, while another 26.03 percent are male. This finding is similar to any other finding in the literature, in which indicator shows that the population of the female is more diverse and encompassed more than three times the population of the male in the context of higher education.

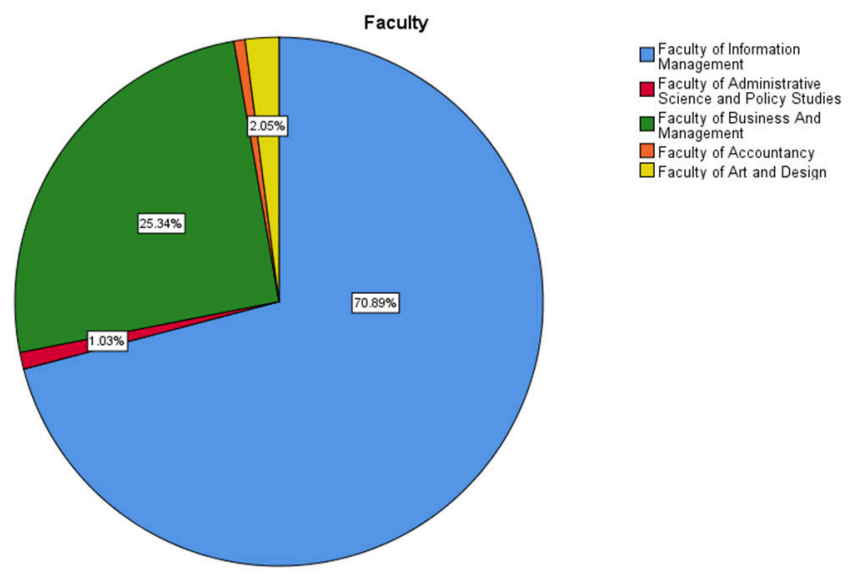

Fig. 2. Faculty

The following figure 2 shows the distribution of respondent based on faculty. 5 faculties involved in this study, namely Faculty of Information Management, Faculty of Administrative Science and Policy Study, Faculty of Business and Management, Faculty of Accountancy, and Faculty of Art and Design. The majority of respondents are from the Faculty of Information 
Management $(70.9 \%$ or $\mathrm{N}=207)$, followed by the Faculty of Business and Management $(25.3 \%$ or $\mathrm{N}=74)$, and Faculty of Art and Design $(2.1 \%$ or $\mathrm{N}=6)$.

\subsection{Descriptive Analysis of Individual Performance}

Table 2. Task Productivity

\begin{tabular}{|c|c|c|c|}
\hline & Item & Mean & Std. Dev \\
\hline TAP1 & $\begin{array}{l}\text { Competencies in referencing enabled me to } \\
\text { complete an academic assignment }\end{array}$ & 4.41 & 1.05 \\
\hline TAP2 & $\begin{array}{l}\text { Competencies in referencing enabled me to } \\
\text { accomplish my academic assignments more } \\
\text { quickly. }\end{array}$ & 4.37 & 1.02 \\
\hline TAP3 & $\begin{array}{l}\text { Competencies in referencing enabled me to } \\
\text { complete my information searching task }\end{array}$ & 4.46 & 1.01 \\
\hline TAP4 & $\begin{array}{l}\text { Competencies in referencing enabled me to } \\
\text { quickly obtain the information I seek. }\end{array}$ & 4.42 & 1.02 \\
\hline TAP5 & $\begin{array}{l}\text { Competencies in referencing increased my } \\
\text { productivity }\end{array}$ & 4.41 & 1.04 \\
\hline
\end{tabular}

Table 2 shows the descriptive analysis for task productivity. There are five items measuring task productivity, labelled as TAP1, TAP2, TAP3, TAP4, and TAP5. A Likert scale of 7 was adopted for the instrument. The item with the highest mean value is "Competencies in referencing enabled me to complete my information searching task". Overall, the mean value for TAP1 $(\mathrm{M}=4, \mathrm{SD}=1.05)$ is 4.41 . The mean value for TAP2 $(\mathrm{M}=4, \mathrm{SD}=1.02)$ is 4.37 . Next, the mean value for TAP3 $(\mathrm{M}=4, \mathrm{SD}=1.01)$ is 4.46 while the mean value for TAP4 $(\mathrm{M}=4, \mathrm{SD}=1.02)$ is 4.42 . Lastly, the mean value for TAP5 $(\mathrm{M}=4, \mathrm{SD}=1.04)$ is 4.41 . The results indicating that respondents have a moderate level of individual performance in term of task productivity as a result of their interaction or experience with the referencing competency.

Table 3. Task Satisfaction

\begin{tabular}{clcc}
\hline & \multicolumn{1}{c}{ Item } & Mean & Std. Dev \\
\hline TAS1 & I am satisfied with my knowledge of referencing. & 4.17 & 1.01 \\
TAS2 & I am satisfied with my skills in referencing & 4.17 & 1.08 \\
TAS3 & I am satisfied with my ability in referencing & 4.15 & 1.07 \\
TAS4 & $\begin{array}{l}\text { Overall, I am very satisfied with my level of competencies in } \\
\text { referencing }\end{array}$ & 4.10 & 1.06 \\
\hline
\end{tabular}

Table 3 shows the descriptive analysis for task satisfaction. There are four items measuring task productivity, labelled as TAS1, TAS2, TAS3, and TAS4. A Likert scale of 7 was adopted for the instrument. The items with the highest mean value are "I am satisfied with my knowledge in referencing" and "I am satisfied with my skills in referencing". Overall, the mean value for TAS1 $(\mathrm{M}=4, \mathrm{SD}=1.01)$ is 4.17 . The mean value for TAS2 $(\mathrm{M}=4, \mathrm{SD}=1.08)$ is 4.17. Next, the mean value for TAS3 $(M=4, S D=1.07)$ is 4.15 while the mean value for TAS4 $(\mathrm{M}=4, \mathrm{SD}=1.06)$ is 4.10 . The results indicating that respondents have a moderate level of individual performance in term of task satisfaction as a result of their interaction or experience with the referencing competency.

\subsection{Discussion}


The conclusion of the research indicating several findings and discussion. First, respondents agreed that the ethical use of information or sources in completing an academic assignment prevents them from plagiarising others' work by giving credit to the rightful authors with appropriate citation. It is important to cite the sources correctly and appropriately in avoiding plagiarism. According to Derakshan, Hassanzadeh and Nazari [25], it is an opportunity for students to learn how to use information ethically if they read the citations of articles and know more about citation style because they noticed how reference is cited. Chankova [26] mentioned that the most plagiarism-free study assignments were also performed by students who obtained the most training in critical thinking, source collection and assessment, paraphrasing and citation.

Second, respondents also agreed that referencing competency helps them to become more literate in finding the appropriate sources. Referencing competency enhanced individual performance by helpings them to find appropriate and relevant sources in completing their information task. University of Liverpool Teaching and Learning Committee [27] defined information literacy competency as "the ability to locate and access information, including using the library catalogue, indexing services, citation services and databases, and using current awareness methods to keep up to date [28].

Third, being competence in referencing helps respondents a lot in completing their information searching task. Respondents may search-related topics and area through backward and forward-searching. A study conducted by Cheng and Tsai [29] found that 9 out of 22 students tracked reference from articles they found for their initial search. Ching- Ting, Yinghsueh [30] in their research also found that tracking article citations by other scholars also is one of the methods of finding relevant articles.

Fourth, the results show that most of the respondence was satisfied with their skills and ability in referencing. Perhaps it can be assumed that the respondents are among higher education students which have gone through the information skill class that exposed them to the right skill for managing their information searching and retrieval. For instance, Library Tun Razak UiTM has conducted the information literacy skill class which give opportunities to the users to join class such as Mendeley and Endnote. These major findings are consistent with Shao and Purpur [31] research that had resulted in the information skill class has affected the students writing ability and skills. 


\section{Conclusion}

This study started with the aim of determining the level of individual performance in the context of referencing competency. Two aspects of individual performance were tested: namely task productivity and task satisfaction. An instrument was developed, pre-tested, pilot study, before field data collection. The data was then analysed based on descriptive analysis using Statistical Package for Social Sciences (SPSS) version 26. The results show that the respondent has a moderate level of task productivity and task satisfaction.

The conduct of this study is not without limitation. First, we only employed the respondent from a single university in Malaysia. Employing more diverse respondents might bring an interesting result. Second, we conceptualize individual performance from the perspective of task productivity and task satisfaction. Future study may consider other variables such as functional benefits, emotional benefits, task innovation, continuing usage, user participation, user involvement, as well as new conceptualization of variables such as user engagement, perceived value, and perceived benefits. Third, we only focus on theory generalization. Future study may consider embarking on population generalization of the theory.

\section{Acknowledgements}

The authors would like to thank the financial support received from Universiti Teknologi MARA Kelantan Branch under Geran Dalaman 600-TNCPI 5/3/DDN (03) (004/2020).

\section{References}

[1] Dario Russo. Competency Measurement Model. European Conference on Quality in Official Statistics (Q2016) Madrid, 31 May-3June 2016. https://www.ine.es/q2016/docs/q2016Final00276.pdf. Page 1-29

[2] Butler, F.C. The concept of competence: An operational definition. Educational Technology 18, no, 1 (1978): 7-18. Accessed February 23, 2021. https://www.learntechlib.org/p/163756/

[3] Kurz, Rainer \& Bartram, Dave. Competency and Individual Performance: Modelling the World of Work. In Organizational Effectiveness: The Role of Psychology, 227-255. Chichester: Wiley, 2002.

[4] Stagg, Adrian, Lindy Kimmins, and Nicholas Pavlovski. Academic style with substance. The Electronic Library (2013).

[5] Lili Luo. Chat reference competencies: identification from a literature review and librarian interviews. Reference Services Review 35, no. 2 (2007): 195-209.

[6] Lilian Ingutia Oyieke \& Archie L. Dick. Empowering academic librarians for effective e-services: An assessment of Web 2.0 competency levels. The Electronic Library 35, no. 2 (2016): 263-282.

[7] Terri Summey. Emotional Intelligence: A framework for the competencies and traits of reference and user services librarians. Advances in Library Administration and Organization, 37, (2017): 129-146. 
[8] Van Der Klink, M. R., \& Boon, J. Competencies: The triumph of a fuzzy concept. International of Human Development and Management, 3, no. (2003).

[9] Boyatzis, R. E. Competencies in the 21st century. The Journal of Management Development, 27, no. 1 (2008).

[10] Oosterbeek, H., van Praag, M., \& Ijsselstein, A. The impact of entrepreneurship education on entrepreneurship skills and motivation. European Economic Review, 54, no. 3 (2010).

[11] Okoye, Michael Onuchukwu. Assessment of competencies of professional librarians in Nigeria. Assessment 6 (2013): 21-2013.

[12] Bronstein, J. An exploration of the library and information science professional skills and personal competencies: An Israeli perspective. Library \& Information Science Research, 37, no. 2 (2015).

[13] Partridge, H., Lee, J., \& Munro, C. Becoming 'librarian 2.0': The skills, knowledge, and attributes required by library and information science professionals in a Web 2.0 world (and beyond). Library Trends, 59 (2010).

[14] Trembach, S., Deng, L., \& Thomas, A. (2012). What does it take them just to get the job? An analysis of employability skills of today's LIS graduates: implications for LIS curricula. Poster session presented at the CCI Annual Research Symposium, Knoxville, (2012), http://trace.tennessee.edu/ccisymposium/2012/poster/13/).

[15] Saunders, L., Kurbanoglu, S., Wilkins-Jordan, M., Boustany, J., Chawner, B., Filas, M., et al. Culture and competencies: A multi-country examination of reference service competencies. Libri, 63 (2013).

[16] Robati, A. P., \& Singh, D. Competencies required by special librarians: An analysis by educational levels. Journal of Librarianship and Information Science, 45, (2013).

[17] Chow, A. S., Shaw, T. L., Gwynn, D., Martensen, D., \& Howard, M. Changing times and requirements: Implications for LIS Education. LIBRES: Library \& Information Science Research Electronic Journal, 21, no. 1, (2011).

[18] Yale University Library. The secretary's commission for achieving the necessary skills (SCANS) for the workplace. (2000), http://www.library.yale .edu/training/stod/competencies.htm

[19] Thomas, J. Computer skills for academic librarians. (1994), http://faculty.canton.edu/thomasj/ALBANY.htm

[20] Nickerson, R. S. The teaching of thinking and problem solving. In Thinking and problem solving, 2, Edited by: Sternberg, R. J. 409-450. (San Diego, CA: Academic Press, 1994).

[21] McCullen, C. Tactics and resources to help students avoid plagiarism. Multimedia Schools, 10, no. 6 (2003).

[22] University of Washington Libraries (2021). Citation Styles \& Tools: Citation Management Software. (2021), https://guides.lib.uw.edu/research/citations/citationtools

[23] Polit, D. F., \& Beck, C. T. The content validity index: Are you sure you know what is being reported? Critique and recommendations. Research in Nursing \& Health, 29(5) (2006).

[24] Nunnally, J.C: Psychometric theory. 2nd Edition. McGraw-Hill. New York. (1978)

[25] Derakshan, Maryam., Hasanzadeh, Mohammad., \& Nazari, Maryam. Developing Information Literate Librarians: A Study of LIS Academics Pedagogical Approaches in the Development of Information Literacy Competencies. The Journal of Academic Librarianship 41, no.6 (2015). 
[26] Chankova, Mariya. Dealing with students' plagiarism pre-emptively through teaching proper information exploitation. International Journal for the Scholarship of Teaching and Learning 11 (2). (2017)

[27] Information Literacy Standards (Liverpool: University of Liverpool Teaching and Learning Committee, 2007). http://www.liv.ac.uk/library /using/literacy.pdf

[28] Anunobi, Chinwe, \& Udem, Oniora Kingsley. Information Literacy Competencies: A Conceptual Analysis. Journal of Applied Information Science and Technology 7 (2). (2014)

[29] Cheng, Y.-H. \& Tsai, C.-C. Online research behaviors of engineering graduate students in Taiwan. Educational Technology \& Society 20 (1). (2017)

[30] Ching- Ting, Hsin, Ying-Hsueh, Cheng, \& Chin- Chung, Tsai. Searching and sourcing online academic literature: Comparisons of doctoral students and junior faculty in education. Online Information Review 40, no. 7 (2016).

[31] Shao, X. and G. Purpur. Effects of Information Literacy Skills on Student Writing and Course Performance. The Journal of Academic Librarianship 42(6). (2016). 